\title{
Modulating carboxymethylcellulose-based hydrogels with superior mechanical and rheological properties for future biomedical applications
}

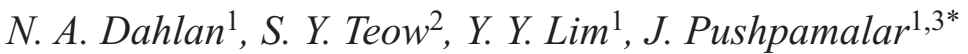 \\ ${ }^{1}$ School of Science, Monash University Malaysia, Jalan Lagoon Selatan, 47500 Bandar Sunway, Selangor, Malaysia \\ ${ }^{2}$ Department of Medical Sciences, School of Healthcare and Medical Sciences, Sunway University, Jalan Universiti, \\ 47500 Bandar Sunway, Selangor, Malaysia \\ ${ }^{3}$ Monash-Industry Palm Oil Education and Research Platform (MIPO), Monash University Malaysia, Jalan Lagoon \\ Selatan, 47500 Bandar Sunway, Selangor, Malaysia
}

Received 22 September 2020; accepted in revised form 10 January 2021

\begin{abstract}
Herein, a grafted copolymer composed of carboxymethylcellulose (CMC) and polyethylene-glycol-aminated $\left(\mathrm{PEG}-\mathrm{NH}_{2}\right)$ was successfully synthesized via a facile ionic interaction and scalable route in the presence of EDC/NHS ( $N$ ethyl- $N$ '-(3-dimethylaminopropyl)carbodiimide/ $N$-hydroxysuccinimide) activators. From Fourier transform infrared (FTIR) spectroscopy, the absorption peak at $1652 \mathrm{~cm}^{-1}$ corresponded to $-\mathrm{NH}$ groups of PEG- $\mathrm{NH}_{2}$. After grafting, the grafted CMC-PEG was characterized for surface morphology, crystallinity, functional groups determination, and thermal analysis. No cytotoxicity effect was observed in normal human dermal fibroblasts (NHDFs) cells following exposure to the grafted CMC-PEG up to $2 \mathrm{mg} / \mathrm{ml}$. The rheological studies suggested that the optimized $10 \%(\mathrm{w} / \mathrm{v})$ grafted CMC-PEG hydrogels crosslinked with $5 \%(\mathrm{w} / \mathrm{v})$ citric acid (CA) exhibited better mechanical properties compared to the non-grafted CMC. This work highlights the characterizations of grafted CMC-PEG and demonstrates the potential of grafted CMC-PEG hydrogels crosslinked with CA for advanced 3D-bioprinting or as injectable hydrogels in various biomedical applications such as tissue engineering, wound dressing materials, and drug delivery systems.
\end{abstract}

Keywords: rheology, carboxymethylcellulose, grafted copolymer, hydrogel, normal human dermal fibroblasts (NHDFs)

\section{Introduction}

Polymers modification is an exciting field of study, especially in applied science research. Modification of polymers to produce new polymeric materials through methods such as physical and chemical processes have been extensively studied over the past few decades [1]. The physical process involves blending, irradiation, and oxidation with gases is a direct method to produce new polymeric materials. However, it was reported that the physical blending of two polymers with distinct properties could result in undesirable mechanical strength and water absorption
$[2,3]$. On the other hand, chemically modified polymer through techniques such as grafting has advantages over several physical processes. This includes controllable and specific binding of interest polymer chains through the formation of covalent bonds between chemically reactive functional groups [4].

Carboxymethylcellulose (CMC) is a low-cost natural polysaccharide with a wide range of applications. $\mathrm{CMC}$ is commonly used as a thickener, viscosity modifier, and water retention agent in the food industry as well as textile, flocculation, and oil drilling industries. CMC is known to be non-cytotoxic, 
biocompatible, and biodegradable polysaccharides. Therefore, research on CMC had branched out to more advanced fields such as heavy metals/dyes adsorption, drug delivery systems, and tissue engineering [5-7]. Polyethylene glycol (PEG) is a biocompatible, hydrophilic, and non-immunogenic synthetic polymer. PEG was reported to respond significantly to the change of $\mathrm{pH}$ by swelling and shrinking to increase tissue formation during the early wound healing stage and leads to the release of growth factors embedded in the scaffold matrix. Besides, most PEGs with molecular weight less than $1000 \mathrm{~g} / \mathrm{mol}$ can be removed rapidly from the body system, thus contributes to its wide usage in biomedical applications such as drug delivery systems and scaffolds for tissue engineering [8]. According to Ghorpade et al. [9], the reactive hydroxyl end terminal $(-\mathrm{OH})$ of PEG can be easily activated and replaced with different functional groups such as azide, carboxyl acid, thiol, and amine. Functionalization of synthetic polymers diversified their potentials as biomaterials in the biomedical field.

The advantage of CMC to develop biomaterials originates from its abundant functional groups such as hydroxyl $(-\mathrm{OH})$ and carboxylate $\left(-\mathrm{COO}^{-}\right)$groups. Therefore, copolymerization of $\mathrm{CMC}$ as the main backbone with different polymers to improve its physical and chemical properties are feasible with minimal changes to its nature. Kumar and Negi [10] reported the synthesis of CMC-graft-poly(sodium 1-hydroxyacrylate) (CMC-g-PnaHA). The grafted copolymers demonstrated 427 times higher water uptake capacity and better thermal stability compared to CMC and PnaHA, respectively. In another study by Alange et al. [11], polyacrylamide-graftCMC (PAAm-g-CMC) showed promising potential as microspheres carriers to deliver capecitabine for the colon drug delivery system. Dahlan et al. [12] reported the synthesis of CMC-graft-polyvinyl alcohol (CMC-g-CMPVA) with smart swelling behavior in different $\mathrm{pH}$ environments and biocompatible to living cells.

Most hydrogels are promising candidates for various biomedical applications due to their biocompatible nature and could provide a 3D environment with a high water content to support cell regeneration [13]. Furthermore, hydrogels are an appealing material for tissue engineering due to their structural similarity to the extracellular matrix (ECM) of tissues and can be applied in a minimally invasive manner. Besides, the fabrication of hydrogels can be done under relatively mild conditions [14]. Many studies reported the potential of CMC-based hydrogels for various biomedical applications ranging from drug carriers for drug delivery, wound dressing materials to injectable hydrogels and scaffolds for tissue engineering [15-19].

In this work, grafted CMC-PEG was synthesized through two simple reaction steps represented in Figure 1. The structural properties of the synthesized grafted CMC-PEG were characterized by Fourier transform infrared (FTIR), carbon and proton nuclear magnetic resonance (NMR) to confirm the grafting of PEG-NH$H_{2}$ to CMC. Furthermore, the surface morphology, crystallinity, thermal behavior, and cytotoxicity of the synthesized product were also studied. The rheological study was performed to study the potential of grafted CMC-PEG hydrogel as hydrogel scaffolds, injectable hydrogels, and hydrogels inks in 3D-printing for future biomedical applications.

\section{Experimental}

\subsection{Materials}

Carboxymethyl cellulose, sodium salt $(\mathrm{CMC})\left(M_{\mathrm{w}}=\right.$ $135000 \mathrm{~g} / \mathrm{mol}$, degree of substitution $(D S)=0.85)$, triethylamine, sodium carbonate $\left(\mathrm{Na}_{2} \mathrm{CO}_{3}\right)$ and $\mathrm{N}$-hydroxysuccinimide (NHS) were purchased from Nacalai Tesque, Japan. $N$-ethyl- $N$ '-(3-dimethylaminopropyl)carbodiimide (EDC), $\rho$-toluenesulfonyl chloride were purchased from Sigma-Aldrich, USA. Polyethylene glycol $\left(M_{\mathrm{W}}=4000 \mathrm{~g} / \mathrm{mol}\right)$, sodium chloride $(\mathrm{NaCl})$, and glycine were supplied by Merck, Germany. Dichloromethane (DCM), magnesium sulfate anhydrous $\left(\mathrm{MgSO}_{4}\right)$, potassium chloride $(\mathrm{KCl})$, citric acid, and hydrochloric acid $(\mathrm{HCl})$ were purchased from Friendemann Schmidt, Australia, while 30\% ammonia solution, potassium dihydrogen phosphate $\left(\mathrm{KH}_{2} \mathrm{PO}_{4}\right)$ and 2-propanol were purchased from $\mathrm{R} \& \mathrm{M}$ Chemicals, United Kingdom. Ninhydrin reagent was obtained from Fisher Scientific, United States (US) while disodium hydrogen phosphate $\left(\mathrm{Na}_{2} \mathrm{HPO}_{4}\right)$ was supplied by HmBG Chemicals, Germany. MTS 3(4,5-dimethylthiazol-2-yl)-5-(3-carboxymethoxyphenyl)-2-(4-sulfophenyl)-2H-tetrazolium was purchased from Promega Corporation, USA. Fibroblast basal medium, fetal calf serum (FCS), human basic fibroblast growth factor (hbFGF), and insulin solution were purchased from PromoCell $\mathrm{GmbH}$, Heidelberg, Germany. Dichloromethane was dried over 
magnesium sulfate while $\rho$-toluenesulfonyl chloride was re-crystallized using acetone before use.

\subsection{Method}

\subsubsection{Synthesis of PEG-NH}

The modification of hydroxyl groups $(-\mathrm{OH})$ of PEG with amine groups $\left(-\mathrm{NH}_{2}\right)$ groups was performed according to Cameron et al. [20] with modification. Briefly, PEG $(10 \mathrm{~g})$ was dissolved in $100 \mathrm{ml}$ of dry dichloromethane. After the addition of triethylamine $(7.5 \mathrm{ml})$, the solution was cooled to $0{ }^{\circ} \mathrm{C}$. Then, $p$-toluenesulfonyl chloride $(5 \mathrm{~g})$ was added and stirred overnight at room temperature. The residue was filtered from the solution, and the filtrate was washed using a separatory funnel with $30 \mathrm{ml}$ of $1 \mathrm{M}$ sodium carbonate solution to remove unreacted $p$ toluenesulfonyl chloride. The bottom layer was extracted for subsequent neutralization. Then, $30 \mathrm{ml}$ of $10 \% \mathrm{HCl}$ for neutralizing the filtrate was added to the bottom layer. The bottom layer containing PEGtosylate was extracted while the upper layer was removed. The remaining solvent was then removed by rotary evaporation. Next, the yellow product $(10 \mathrm{~g})$ was dissolved in $25 \%$ aqueous ammonia solution $(150 \mathrm{ml})$, and the reaction mixture was vigorously stirred for 3 days at room temperature. The reacted mixture was left overnight to evaporate the ammonia. The basic solution containing remaining ammonia was extracted three times with DCM using a separatory funnel, and finally, the DCM was removed by rotary evaporation.

\subsubsection{Grafting of PEG-NH $\mathrm{N}_{2}$ onto CMC}

For the synthesis of grafted CMC-PEG, 2\% (w/v) $\mathrm{CMC}$ and PEG-NH $\mathrm{N}_{2}$ were separately dissolved in distilled water. Subsequently, the activating agents of EDC and NHS (2:1) were added to the CMC solution to activate the reaction, followed by the addition of dissolved PEG-NH $\mathrm{N}_{2}$. In this study, EDC coupled with NHS was used to activate the carboxyl groups of CMC to form a stable amide bond with primary amines of $\mathrm{PEG}-\mathrm{NH}_{2}$ [21]. The final concentration of the reaction mixture was $\mathrm{CMC}(0.07 \mathrm{mM}), \mathrm{PEG}^{-\mathrm{NH}_{2}}$ (2.50 mM), EDC (9.66 mM), and NHS (6.52 mM). The reaction took place at room temperature for 24 hours by stirring in a sealed beaker. To remove unbound PEG-NH $\mathrm{N}_{2}$, the solution was dialyzed against distilled water overnight. Finally, the product was dried to constant weight. The grafted CMC-PEG solid was grounded and sieved through $150 \mu \mathrm{m}$ and stored in a desiccator for subsequent analyses. The percentage yield of the final was calculated by Equation (1):

Percentage yield $[\%]=\frac{W_{\mathrm{f}}}{W_{\mathrm{c}}} \cdot 100$

where $W_{\mathrm{f}}$ denotes the weight of grafted CMC-PEG and $\mathrm{W}_{\mathrm{c}}$ represents the initial weight of CMC.

\subsubsection{Degree of grafting}

The degree of grafting was determined by ninhydrin assay. First, approximately $100 \mathrm{mg}$ of grafted CMCPEG was heated with the ninhydrin reagent $(2 \%(\mathrm{w} / \mathrm{v})$ in 2-propanol) at $100^{\circ} \mathrm{C}$ for 15 minutes. The PEG$\mathrm{NH}_{2}$ sample was considered as the control. The solution was cooled at room temperature, and the optical absorbance was recorded at $570 \mathrm{~nm}$ using a spectrophotometer. The amount of $-\mathrm{NH}_{2}$ groups was determined from a standard curve of glycine concentration versus absorbance. The degree of grafting was calculated by Equation (2):

Degree of grafting [\%] $=\frac{\mathrm{NH}_{\mathrm{i}}-\mathrm{NH}_{\mathrm{f}}}{\mathrm{NH}_{\mathrm{i}}} \cdot 100$

where $\mathrm{NH}_{\mathrm{i}}$ and $\mathrm{NH}_{\mathrm{f}}$ represent the amount of free amine groups before and after grafting.

\subsubsection{Characterization}

The surface morphology of the synthesized grafted CMC-PEG was examined on a Hitachi SU8010 field emission electron microscope (FESEM). The sample was sputter-coated with platinum after mounting on double-sided carbon tape. The infrared spectra of PEG, PEG-NH ${ }_{2}, \mathrm{CMC}$, and grafted CMC-PEG were taken in the range of $400-4000 \mathrm{~cm}^{-1}$ using Spectrum-Two FT-IR spectrophotometer, Perkin Elmer, Inc. XRD patterns of PEG, PEG-NH $\mathrm{N}_{2}, \mathrm{CMC}$, and grafted CMC-PEG powdered samples were recorded in the range of $5-60^{\circ}$ at ambient temperature on BRUKER D8 Discover X-ray Diffraction system. Percentage crystallinity was calculated using Equation (3) [22]:

Percentage crystallinity $[\%]=\frac{A_{\mathrm{c}}}{A_{\mathrm{c}}+A_{\mathrm{a}}} \cdot 100$

where $A_{\mathrm{c}}$ represents the area of the crystalline peak while $A_{\mathrm{a}}$ is the area of the amorphous peak.

Molecular weights and polydispersities of PEG-NH and grafted CMC-PEG were determined by gel permeation chromatography (GPC, Tosoh EcoSEC HLC-8320GPC) equipped with both refractive index 
$(R I)$ and ultraviolet (UV detection, $\lambda=280 \mathrm{~nm}$ ) detectors using Tosoh alpha 4000 and 2000 columns. The solvent and mobile phase was water containing $0.1 \mathrm{M} \mathrm{NaNO}_{3}$ and $0.1 \mathrm{M} \mathrm{NaHCO}_{3}$ with a flow rate of $1 \mathrm{ml} / \mathrm{min}$. The calibration curves were obtained using $10 \times$ low dispersity PEG/PEO standards (PEG/ PEO: $\left.615-1.38 \cdot 10^{6} \mathrm{~g} / \mathrm{mol}, R^{2}=0.9995\right) .{ }^{1} \mathrm{H}$ NMR (nuclear magnetic resonance) of grafted CMC-PEG was recorded at $30^{\circ} \mathrm{C}$ in $\mathrm{D}_{2} \mathrm{O}$ using BRUKER $500 \mathrm{MHz}$ FT-NMR with a relaxation delay time of 1 second. ${ }^{13} \mathrm{C}$ cross-polarization magic angle spinning (CPMAS) was recorded using a Bruker BioSpin $\mathrm{GmbH}$ operating at $75.44 \mathrm{MHz}$. In CPMAS experiment, the sample was spun at $10 \mathrm{kHz}$. For differential scanning calorimetry, approximately $5 \mathrm{mg}$ of $\mathrm{CMC}$, PEG, PEG-NH ${ }_{2}$, and grafted CMC-PEG powdered samples were analyzed by DSC Q100 in a platinum crucible scan with a scan speed of $20^{\circ} \mathrm{C} / \mathrm{min}$ over a temperature range of -50 to $200^{\circ} \mathrm{C}$ under constant nitrogen. The samples were pre-dried in the oven overnight prior to the analysis. The following protocol was used for each sample: equilibrate at $-50^{\circ} \mathrm{C}$ and isothermal for $1 \mathrm{~min}$, heating to $200^{\circ} \mathrm{C}$ and isothermal for $1 \mathrm{~min}$, cooling to $-50^{\circ} \mathrm{C}$ and isothermal for $1 \mathrm{~min}$, and finally reheating to $200^{\circ} \mathrm{C}$. Data was collected from the second heating curve. The thermograms of CMC, $\mathrm{PEG}, \mathrm{PEG}-\mathrm{NH}_{2}$, and grafted CMC-PEG were obtained using TGA Q500 V6.7 Build 203 device. Approximately $5 \mathrm{mg}$ samples were analyzed with temperatures ranging from 25 to $700^{\circ} \mathrm{C}$ under nitrogen.

\subsubsection{Cell cytotoxicity study}

\section{Cell culture}

Normal human dermal fibroblasts (NHDFs) was cultured in fibroblast basal medium (FBM) supplemented with $2 \%(\mathrm{v} / \mathrm{v})$ fetal bovine serum (FBS), $1 \mathrm{ng} / \mathrm{ml}$ basic fibroblast growth factor (hbFGF), $5 \mu \mathrm{g} / \mathrm{ml}$ insulin solution, $100 \mathrm{U} / \mathrm{ml}$ penicillin and $100 \mu \mathrm{g} / \mathrm{ml}$ streptomycin in a $25 \mathrm{~cm}^{2}$ cell culture flask. The NHDFs cells were then incubated in a humidified atmosphere $(95 \%)$ containing $5 \% \mathrm{CO}_{2}$ at $37^{\circ} \mathrm{C}$. The culture medium was changed every three days.

\section{Quantitative cell viability MTS assay}

The cytotoxicity of grafted CMC-PEG at different concentrations was determined using MTS colorimetric assay. Before the experiments, $10 \mathrm{mg}$ of powdered grafted CMC-PEG were sterilized by UV light for $60 \mathrm{~min}$, followed by the addition of $500 \mu \mathrm{l}$ of sterile water, and incubated in the oven at $80^{\circ} \mathrm{C}$ until dissolution. The stock polymer solution with $10 \mathrm{mg} / \mathrm{ml}$ concentration was achieved by adding $500 \mu \mathrm{l}$ of FBM media to the dissolved polymer solution. Subsequently, test samples containing grafted CMC-PEG with concentrations ranging from 0.00001 to $10 \mathrm{mg} / \mathrm{ml}$ were prepared by diluting the stock solution. NHDFs cells with a density of $2.5 \cdot 10^{4}$ cells $/ \mathrm{ml}$ were seeded onto a 96 -well sterile tissue culture plate (TCP) containing $100 \mu 1 \mathrm{FBM}$ and kept in the incubator at $37^{\circ} \mathrm{C}$ for $24 \mathrm{~h}$. Subsequently, the FBM medium in each NHDFs seeded well was replaced with $100 \mu \mathrm{l}$ of the prepared grafted CMC-PEG at different concentrations $\left(C P_{\mathrm{e}}\right)$. Furthermore, NHDFs seeded with FBM acted as the control $\left(\mathrm{NHDF}_{\mathrm{c}}\right)$ while non-seeded wells with either grafted CMC-PEG solutions with different concentrations $\left(C P_{\mathrm{b}}\right)$ or FBM medium $\left(F_{\mathrm{b}}\right)$ served as the blank. The prepared TCP was incubated for $24 \mathrm{~h}$. At the end of the time-point, $10 \mu 1$ of MTS solution was added to the wells, followed by incubation at $37^{\circ} \mathrm{C}$ for $3 \mathrm{~h}$. Then, the optical density $(O D)$ values were measured at a wavelength of $490 \mathrm{~nm}$ using a Microplate reader. The relative cell viability was calculated by Equation (4):

Cell viability $[\%]=\frac{O D C P_{\mathrm{e}}-O D C P_{\mathrm{b}}}{O D \mathrm{NHDF}_{\mathrm{c}}-O D F_{\mathrm{b}}} \cdot 100$

\subsubsection{Grafted CMC-PEG hydrogel preparation} In this study, $10 \%(\mathrm{w} / \mathrm{v})$ grafted CMC-PEG was prepared by dissolving the polymer in distilled water. The polymer solution was incubated in the oven at $80^{\circ} \mathrm{C}$ to ensure complete dissolution. For the crosslinking of hydrogels with citric acid (CA), the dissolved grafted CMC-PEG was crosslinked with 5, 10, and $15 \%(\mathrm{w} / \mathrm{v})$ of $\mathrm{CA}$, indicated by $10 \% \mathrm{CMC}^{-\mathrm{PEG}_{5}}$, $10 \% \mathrm{CMC}_{\mathrm{CEG}} \mathrm{PE}_{10}$, and $10 \% \mathrm{CMC}_{\mathrm{CEG}} \mathrm{P}_{15}$, respectively before the analysis. The hydrogels were incubated in the oven at $37^{\circ} \mathrm{C}$ overnight during the crosslinking process. On the other hand, 2.5\% (w/v) CMC was dissolved at room temperature. Then, the same steps were repeated for preparing $2.5 \%(\mathrm{w} / \mathrm{v})$ cross-linked with 5,10 and $15 \%(\mathrm{w} / \mathrm{v})$ of CA denoted as $2.5 \%$ CMC5, 2.5\% $\mathrm{CMC}_{10}$ and 2.5\% $\mathrm{CMC}_{15}$, respectively.

\subsubsection{Rheology analysis}

Rheology measurements were performed at $25^{\circ} \mathrm{C}$ on an Anton Paar MCR 302 rheometer. The measurements were performed using a sand blasted-type 
geometry ( $25 \mathrm{~mm}$ in diameter). The storage modulus $\left(G^{\prime}\right)$ and loss modulus $\left(G^{\prime \prime}\right)$ of materials were measured in oscillatory mode at $25^{\circ} \mathrm{C}$. For amplitude sweep measurement, the hydrogel materials were tested for strain values of 0.01 to $1000 \%$ by keeping the angular frequency constant at $10 \mathrm{~Hz}$. In the frequency sweep measurement, the hydrogel materials were tested from 0.1 to $100 \mathrm{rad} / \mathrm{s}$ frequency range by keeping constant the shear strain constant at $0.5 \%$.

\subsubsection{Statistical analysis}

Data were analyzed by one-way analysis of variance (ANOVA) using GraphPad Prism Version 8.1.2 for Windows (GraphPad Software, Inc.) and presented as mean \pm standard deviation for triplicates with $p<0.05$.

\section{Results and discussion}

\subsection{Synthesis of grafted CMC-PEG}

In this study, the amine groups of functionalized PEG-NH $\mathrm{N}_{2}$ were grafted to the reactive carboxyl groups on the backbone of CMC via a 'grafting to' approach. In this approach, new properties will be introduced to the newly grafted product while maintaining the desirable properties of each polymer substrate $[23,24]$. First, $\mathrm{PEG}-\mathrm{NH}_{2}$ was modified through asymmetric activation of symmetrical PEG. PEG-tosylate was then synthesized as a precursor before the amination process, as shown in Figure 1a. Tosylate groups are excellent candidates for substitution reactions to enable the conversions of different functional groups [25]. Formation of grafted CMC-PEG was achieved through coupling reaction of EDC/NHS. In this case, EDC activated the carboxyl group of CMC to form an unstable amine-reactive intermediate followed by coupling NHS that rearranged the intermediate into a more stable amine-reactive ester. A stable amide bond was then created between $\mathrm{CMC}$ and PEG-NH to form grafted CMC-PEG $[21,26]$. Based on the grafting reaction scheme of grafted CMC-PEG illustrated in Figure 1(b), the grafting of PEG-NH $\mathrm{NH}_{2}$ could be alternately random on the $\mathrm{CMC}$ backbone.

According to Kumar et al. [27], ninhydrin causes oxidative deamination of $-\mathrm{NH}_{2}$ releasing ammonia $\left(\mathrm{NH}_{3}\right)$ followed by condensation of reduced ninhydrin to form colored substances. Therefore, the degree of $\mathrm{PEG}-\mathrm{NH}_{2}$ grafted onto the $\mathrm{CMC}$ backbone was investigated using the ninhydrin assay. A similar approach was used by Baharifar et al. [28] to measure the amount of free amines of deacetylated chitosan conjugated to PEG. The free amine groups of PEG-NH $\mathrm{N}_{2}$ were measured using ninhydrin method before and after the grafting process. It was found that $71 \%$ of $\mathrm{PEG}-\mathrm{NH}_{2}$ was successfully grafted to CMC. Meanwhile, a percentage yield of $177 \%$ was obtained after the grafting of PEG-NH $\mathrm{N}_{2}$ to $\mathrm{CMC}$. The high yield indicates an ideal CMC-PEG grafting approach for large-scale production of polymeric biomaterials.

\subsection{Field emission electron microscope (FESEM)}

Figure 2a shows the granule morphology of grafted CMC-PEG. The granular appearance of grafted

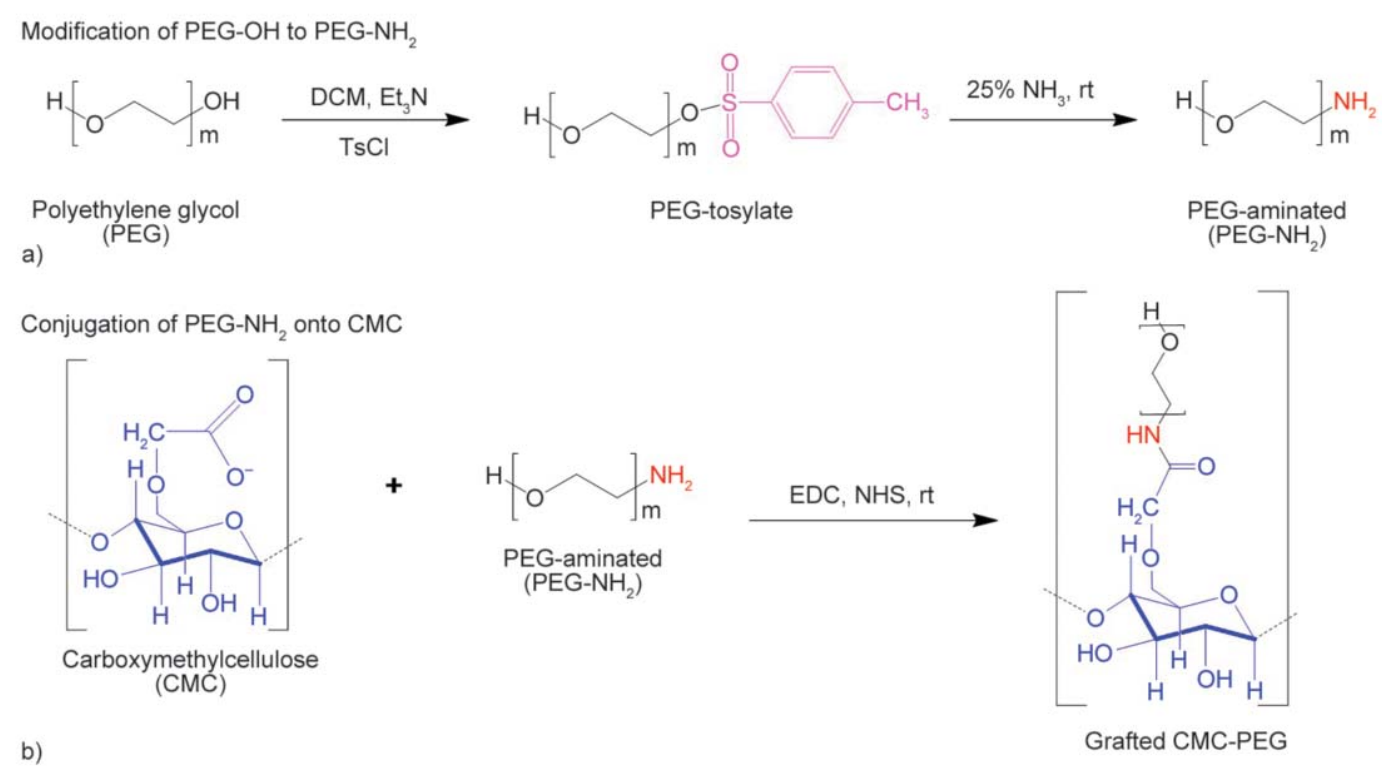

Figure 1. Schematic representations of (a) modification of $\mathrm{PEG}-\mathrm{OH}$ to $\mathrm{PEG}-\mathrm{NH}_{2}$ and (b) the grafting of $\mathrm{PEG}-\mathrm{NH}_{2}$ to $\mathrm{CMC}_{\text {. }}$ 


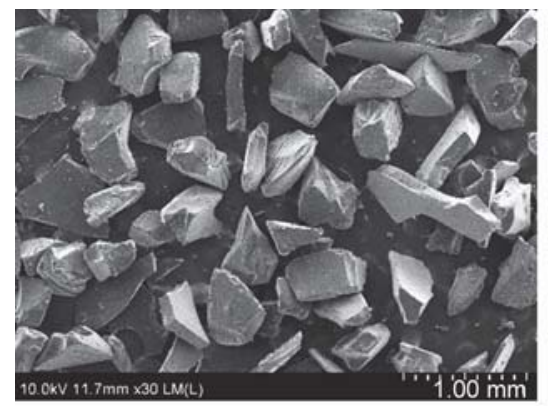

a)

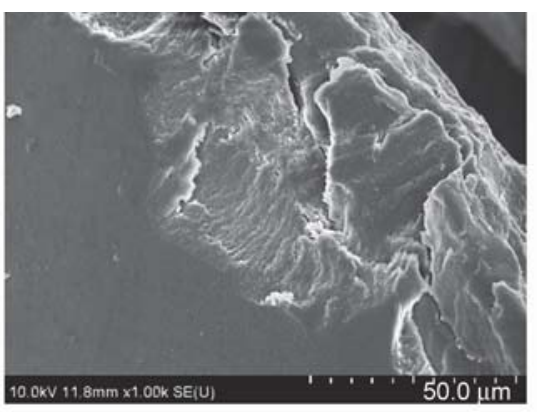

b)

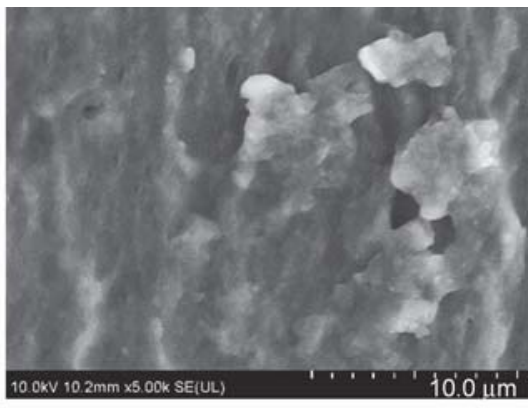

c)

Figure 2. Surface morphology of grafted CMC-PEG at (a) $\times 30$, (b) $\times 1000$ and (c) $\times 5000$ magnifications.

CMC-PEG at higher magnification showed a smooth surface with rough edges, as shown in Figure $2 b$ and $2 \mathrm{c}$.

\subsection{Fourier transform infrared (FT-IR) and $\mathrm{X}$-ray diffraction (XRD) analyses}

Fourier transform infrared spectroscopy was used to characterize and identify the functional groups of PEG, PEG-NH ${ }_{2}, \mathrm{CMC}$, and grafted CMC-PEG, as shown in Figure 3a. The infrared spectrum of CMC showed a broad spectrum at $3288 \mathrm{~cm}^{-1}$, which represents the - $\mathrm{OH}$ stretching of non-substitute hydroxyl groups of the cellulose. An absorption band at $2886 \mathrm{~cm}^{-1}$ exhibited $-\mathrm{CH}$ stretching vibration. According to the literature, the bands caused by $-\mathrm{CO}$ stretching of the ether linkage [1,4- $\beta$-D-glucoside] or the ether group outside and inside the ring of cellulose carboxymethylation can be detected $1024 \mathrm{~cm}^{-1}$ [12]. The absorption bands at 1590, 1416, and 1322 were attributed to carbonyl stretch of $-\mathrm{COO}^{-}$, the $-\mathrm{CH}_{2}$ bending of scissoring type and $-\mathrm{CO}$ vibration, respectively. The spectrum of PEG exhibited the characteristic bands attributed to $\mathrm{C}-\mathrm{H}$ bonds at $2750 \mathrm{~cm}^{-1}$ stretching vibration. The broad band centered at $3480 \mathrm{~cm}^{-1}$ was assigned to the $-\mathrm{OH}$ stretching. In addition to that, the band around $1100-1000 \mathrm{~cm}^{-1}$ was assigned to $-\mathrm{COC}$ bonds. After modification with amine groups $\left(\mathrm{NH}_{2}\right)$, the most significant differences can be detected at specific regions ranges from 4000-2500 and 1800$1600 \mathrm{~cm}^{-1}$ as illustrated by the PEG-NH $\mathrm{N}_{2}$ spectrum. The band centered at $3492 \mathrm{~cm}-1$ attributable to $\mathrm{NH} 2$ asymmetric and symmetric stretching. Furthermore, a peak located at $1652 \mathrm{~cm}^{-1}$ was assigned to the primary $-\mathrm{NH}_{2}$ group introduced after the modification as shown in Figure 3b. The grafted CMCPEG exhibited an absorption band at $2874 \mathrm{~cm}^{-1}$ corresponding to the $-\mathrm{CH}$ functional groups. Characteristic bands of $-\mathrm{OH}$ and $-\mathrm{NH}$ at 3504 and $1656 \mathrm{~cm}^{-1}$, indicating that the grafting of $\mathrm{PEG}-\mathrm{NH}_{2}$ to $\mathrm{CMC}$ was successful, as evidenced by the formation of an amide bond. The absorption bands at 1462 and 1354 were attributed to the $-\mathrm{CH}_{2}$ bending of scissoring type and - $\mathrm{CO}$ vibration, respectively. An absorption band at $1108 \mathrm{~cm}^{-1}$ was assigned to the $-\mathrm{COC}$ functional groups.

The diffraction patterns of PEG, PEG-NH 2, CMC, and grafted CMC-PEG are shown in Figure 4. The X-ray diffractogram of PEG showed diffraction peaks at $13.55,19.15,23.27,26.26$, and $27.04^{\circ}$ with
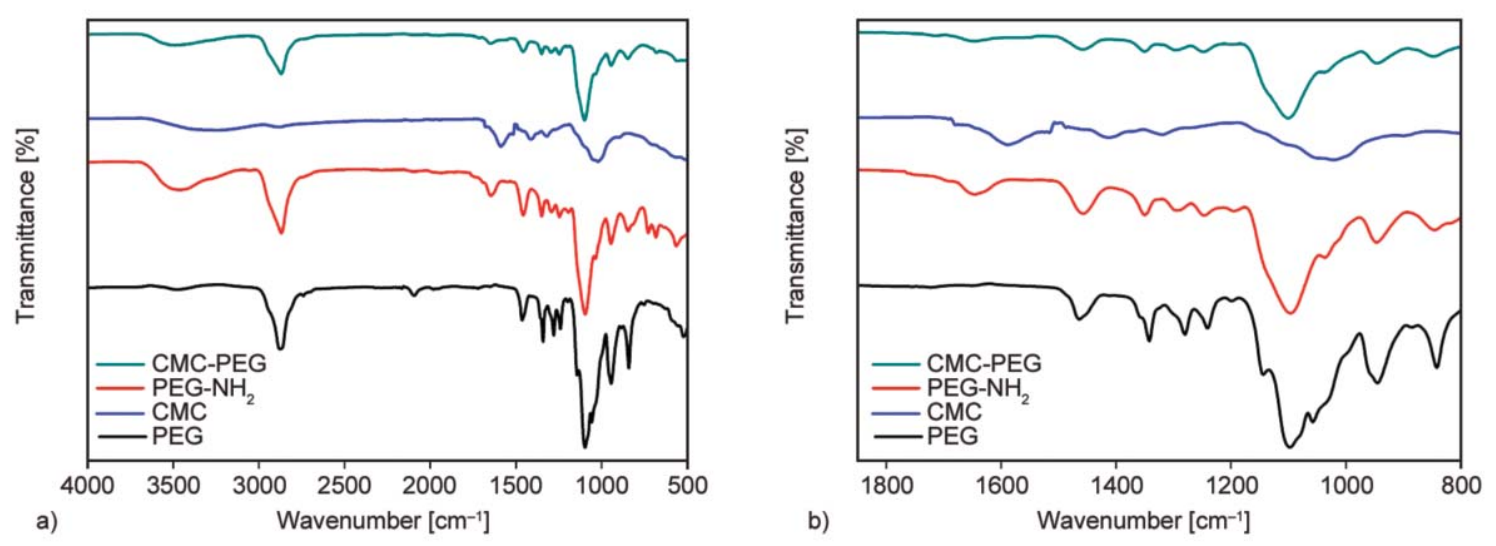

Figure 3. FTIR spectra of PEG, PEG-NH, CMC, and grafted CMC-PEG at (a) 400-4000 $\mathrm{cm}^{-1}$ and (b) $850-1850 \mathrm{~cm}^{-1}$. 


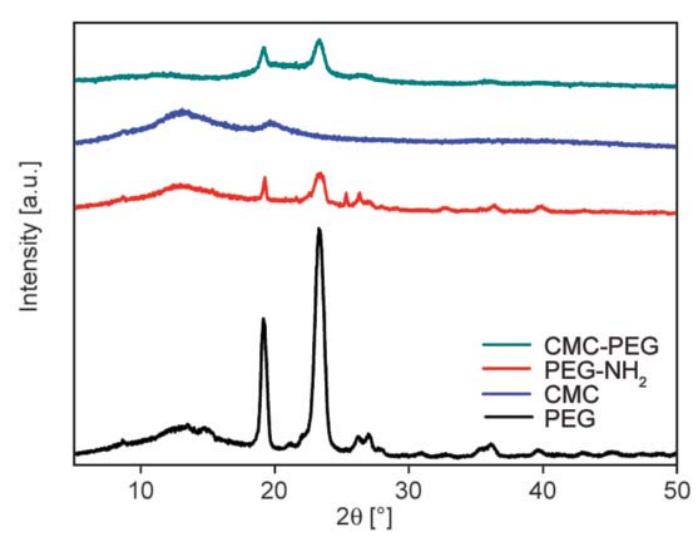

Figure 4. X-ray diffractograms of $\mathrm{PEG}, \mathrm{PEG}_{\mathrm{NH}}$, $\mathrm{CMC}$, and grafted CMC-PEG.

a percentage crystallinity of $97.1 \%$. These are typical peaks for PEG as reported in the literature. Therefore, this indicates the PEG used in this study is of a pure form [29]. Comparing with PEG, the intensity of peaks at $2 \theta=19.23$ and $23.42^{\circ}$ reduced significantly in the XRD spectrum of PEG-NH 2 . Furthermore, the position of peaks at $2 \theta=13.55,26.26$ and $27.04^{\circ}$ have shifted to $13.02,25.30$ and $26.32^{\circ}$, and the percentage crystallinity reduced significantly to $81.1 \%$. According to the literature, the functionalization of $\mathrm{PEG}$ with $-\mathrm{NH}_{2}$ disrupts intermolecular hydrogen bonds leading to lower crystallinity [30]. $\mathrm{CMC}$, having an amorphous nature, shows broad diffraction peaks at $2 \theta=13.09$ and $19.65^{\circ}$ with $53.3 \%$ crystallinity. In contrast, the X-ray diffractogram of grafted CMC-PEG revealed that the crystalline domain anticipated from the presence of PEG- $\mathrm{NH}_{2}$ with well-defined diffraction peaks and reduced intensities at $19.13,23.31$ and $26.63^{\circ}$. This indicates the successful grafting of PEG-NH $\mathrm{N}_{2}$ to the CMC backbone. A broad peak was also detected at $2 \theta=11.66^{\circ}$. The results demonstrated the semi-crystalline nature of grafted CMC-PEG indicated by the mixture of crystalline and amorphous domains. Badwaik et al. [31] reported the disruption of the semi-crystalline nature of carboxymethyl xanthan gum with acrylamide (CMXG-g-PAAm). Similarly, Yang et al. [32] reported a decrease in crystallinity of carboxymethyl $\beta$-cyclodextrin-grafted-carboxymethyl chitosan. Our study found that the percentage crystallinity of grafted CMC-PEG (54.2\%) was significantly lower than PEG-NH $\mathrm{N}_{2}$, yet comparable to the CMC. The formation of covalent bonds between the functionalized polymer and the main polymer chain (the backbone) could affect the chain arrangement, hence reducing the crystallinity [33].

\subsection{Molecular weight analysis}

The molecular weight and polydispersity index of PEG-NH $\mathrm{N}_{2}$ and grafted CMC-PEG obtained from GPC analysis are tabulated in Table 1. The amination of PEG to PEG-NH $\mathrm{N}_{2}$ exhibited a low polydispersity index $(P D I=1.179)$ with uniform polymer chains. After the grafting process, the GPC trace of grafted CMC-PEG shifted towards higher molecular weight regions with lower elution time. As a result, the molecular weight $\left(M_{\mathrm{w}}\right)$ of grafted CMC-PEG $(572034 \mathrm{~g} / \mathrm{mol})$ increased significantly compared to the $M_{\mathrm{w}}$ of CMC $(135000 \mathrm{~g} / \mathrm{mol})$ after being grafted with PEG-NH$H_{2}$. The exceptional $M_{\mathrm{w}}$ and wide $P D I$ of grafted CMC-PEG could be due to the effects of polymer branching, length, and grafting flexibility [34]. Moreover, the high $M_{\mathrm{w}}$ of grafted CMC-PEG supported our calculated percentage yield of $177 \%$ mentioned in Section 3.1. Ciftci [35] reported a similar observation through the synthesis of poly(styrenegraft-poly(ethylene glycol) methacrylate) (PS-gPEGMA).

\subsection{Nuclear magnetic resonance (NMR)}

As shown in Figure 5a, the structure of PEG-NH $\mathrm{NH}_{2}$ was confirmed using ${ }^{1} \mathrm{H}$ NMR. Chemical shift at 2.26 ppm corresponded to the $-\mathrm{NH}_{2}$ groups of PEG$\mathrm{NH}_{2}$. On the other hand, the shift at $3.57 \mathrm{ppm}$ was the proton signals from the oxyethylene chains of $\mathrm{PEG}$ block $\left(-\mathrm{CH}_{2} \mathrm{CH}_{2} \mathrm{O}-\right)$ [36]. Veeramachineni et al. [37] confirmed the structure of carboxymethylcellulose synthesized from sago biomass through the appearance of chemical shifts at 3 and $4 \mathrm{ppm}$ corresponded to the $\mathrm{H} 1$ and $\mathrm{H} 2$ of the glucose units, respectively. The H3-6 protons in the glucose units appeared between 4 to $4.5 \mathrm{ppm}$. Finally, the peaks appearing between 3.8 to $4.4 \mathrm{ppm}$ were assigned to the methylene protons in the substituted carboxymethyl groups. Meanwhile, ${ }^{1} \mathrm{H}$ NMR spectrum of grafted CMC-PEG in $\mathrm{D}_{2} \mathrm{O}$ is shown in Figure $5 \mathrm{~b}$. The sharp peak at $3.65 \mathrm{ppm}$ was assigned to $-\mathrm{CH}_{2} \mathrm{CH}_{2} \mathrm{O}-$ chains of PEG. Similarly, the proton signals of CMC backbone related to $\mathrm{H} 2$ to $\mathrm{H} 6$ in an anhydroglucose unit and

Table 1. GPC data obtained for $\mathrm{PEG}-\mathrm{NH}_{2}$ and grafted CMC-PEG.

\begin{tabular}{|l|r|r|c|}
\hline \multicolumn{1}{|c|}{ Sample } & $\begin{array}{c}\boldsymbol{M}_{\mathbf{n}} \\
{[\mathbf{g} / \mathbf{m o l}]}\end{array}$ & $\begin{array}{c}\boldsymbol{M}_{\mathbf{w}}{ }^{*} \\
{[\mathbf{g} / \mathbf{m o l}]}\end{array}$ & $\begin{array}{c}\boldsymbol{P D I} \\
\left(\boldsymbol{M}_{\mathbf{w}} / \boldsymbol{M}_{\mathbf{n}}\right)\end{array}$ \\
\hline PEG-NH $_{2}$ & 2592 & 3056 & 1.179 \\
\hline Grafted CMC-PEG & 226287 & 572034 & 2.528 \\
\hline
\end{tabular}

${ }^{*}$ theoretical $M_{\mathrm{w}}$ of PEG and CMC were $4000 \mathrm{~g} / \mathrm{mol}$ and $135000 \mathrm{~g} / \mathrm{mol}$, respectively. 

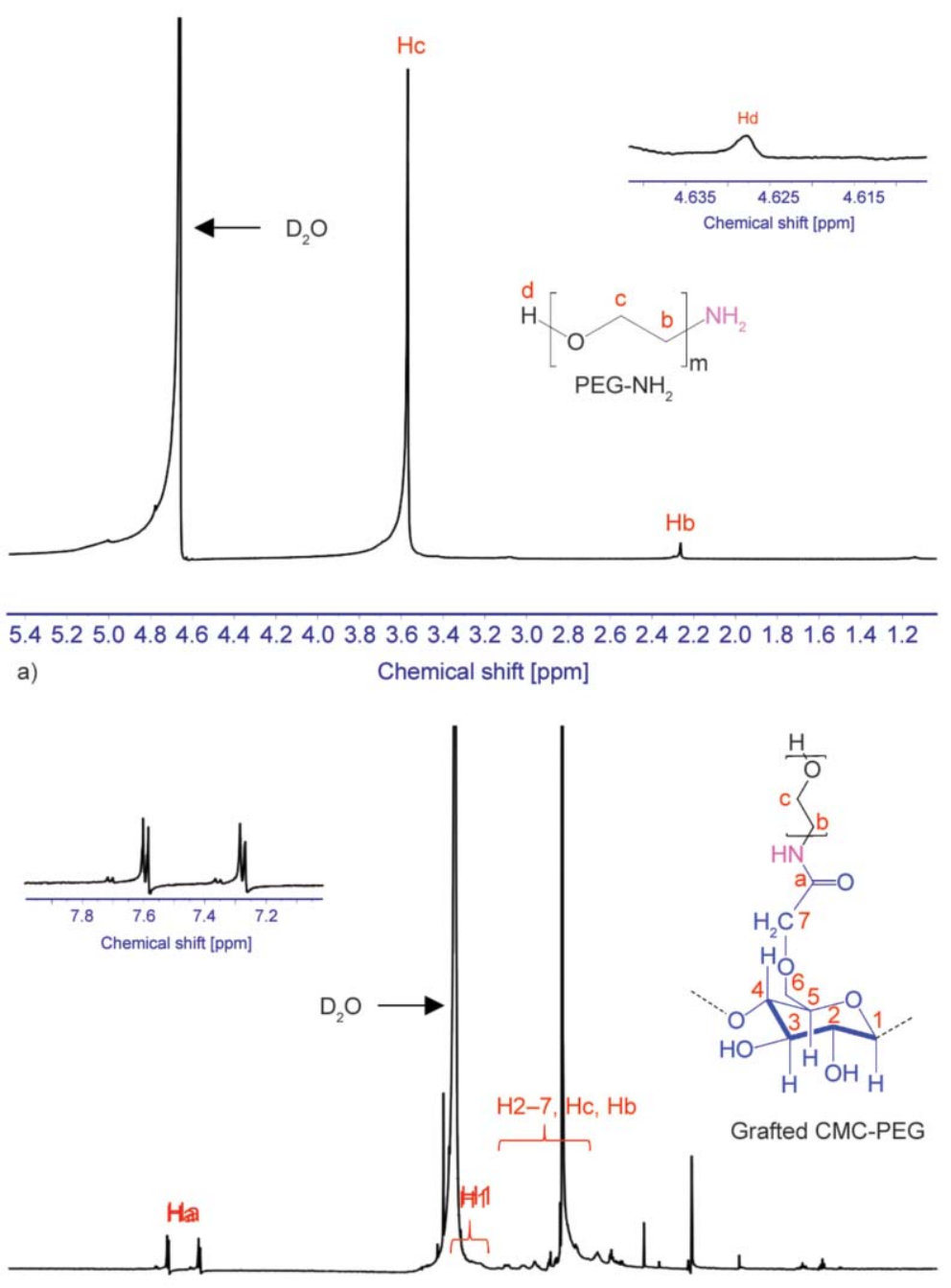

$\begin{array}{lllllllllllllllllll}9.0 & 8.5 & 8.0 & 7.5 & 7.0 & 6.5 & 6.0 & 5.5 & 5.0 & 4.5 & 4.0 & 3.5 & 3.0 & 2.5 & 2.0 & 1.5 & 1.0 & 0.5 & 0.0\end{array}$

b) Chemical shift [ppm]

Figure 5. ${ }^{1} \mathrm{H}$ NMR of (a) PEG-NH 2 and (b) grafted CMC-PEG.

methylene protons in the substituted carboxymethyl groups appeared as broad regions between 3.60 to 4.23 ppm [38, 39]. The grafting of $\mathrm{PEG}-\mathrm{NH}_{2}$ onto the $\mathrm{CMC}$ chain was confirmed through the proton on the amide group with characteristic peaks that appeared between 7.31 to $7.71 \mathrm{ppm}$. A study by Li et al. [40] observed similar peaks within the same region, to confirm the conjugation of folate to carboxymethyl chitosan through polyethylene glycol spacer (CMCSPEG-FA).

Figure 6 shows the solid-state ${ }^{13} \mathrm{C}$ CPMAS NMR of grafted CMC-PEG. In the ${ }^{13} \mathrm{C}$ CPMAS NMR spectrum, the six carbon atoms in the CMC glucose units appeared within 50-100 ppm. The peaks at 100.21, 94.24, and $70.76 \mathrm{ppm}$ were assigned to $\mathrm{C} 1, \mathrm{C} 4$ and overlapping of $\mathrm{C} 2, \mathrm{C} 3, \mathrm{C} 5$ and $\mathrm{C} 7$ of the CMC. The signal at $58.62 \mathrm{ppm}$ was assigned to C6 [41-43]. On the other hand, the presence of PEG was identified

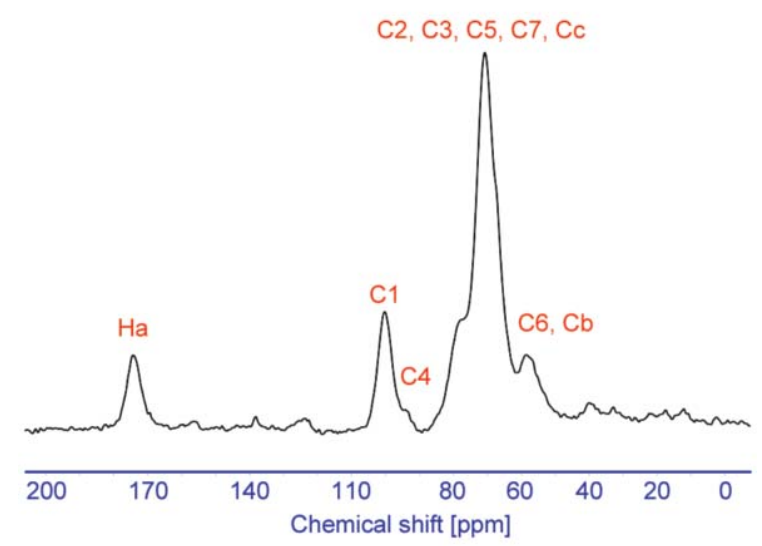

Figure 6. ${ }^{13} \mathrm{C}$ CPMAS NMR of grafted CMC-PEG.

through the appearance of peaks at 70.76, and $58.62 \mathrm{ppm}$ corresponds to the $\mathrm{Cc}$ and $\mathrm{Cb}$. The signal at $174 \mathrm{ppm}$ was specific to the amide bond due to the reaction between the $-\mathrm{NH}_{2}$ groups of $\mathrm{PEG}-\mathrm{NH}_{2}$ and $-\mathrm{COOH}$ groups of $\mathrm{CMC}$. The presence of these 
signals indicated the successful formation of grafted CMC-PEG.

\subsection{Thermal analysis}

Herein, the thermal properties of PEG, PEG- $\mathrm{NH}_{2}$, $\mathrm{CMC}$, and grafted CMC-PEG were studied by DSC and TGA, as shown in Figure 7. The DSC thermogram of CMC showed in Figure 7a indicates that due to the amorphous state of CMC, it did not show any prominent peak after heating to $200^{\circ} \mathrm{C}$. According to the literature, the melting temperature of $\mathrm{CMC}$ was observed around $315^{\circ} \mathrm{C}$ [44]. After PEG modification of the $-\mathrm{OH}$ end terminal to $-\mathrm{NH}_{2}$, it was observed that the endothermic peak that corresponds to
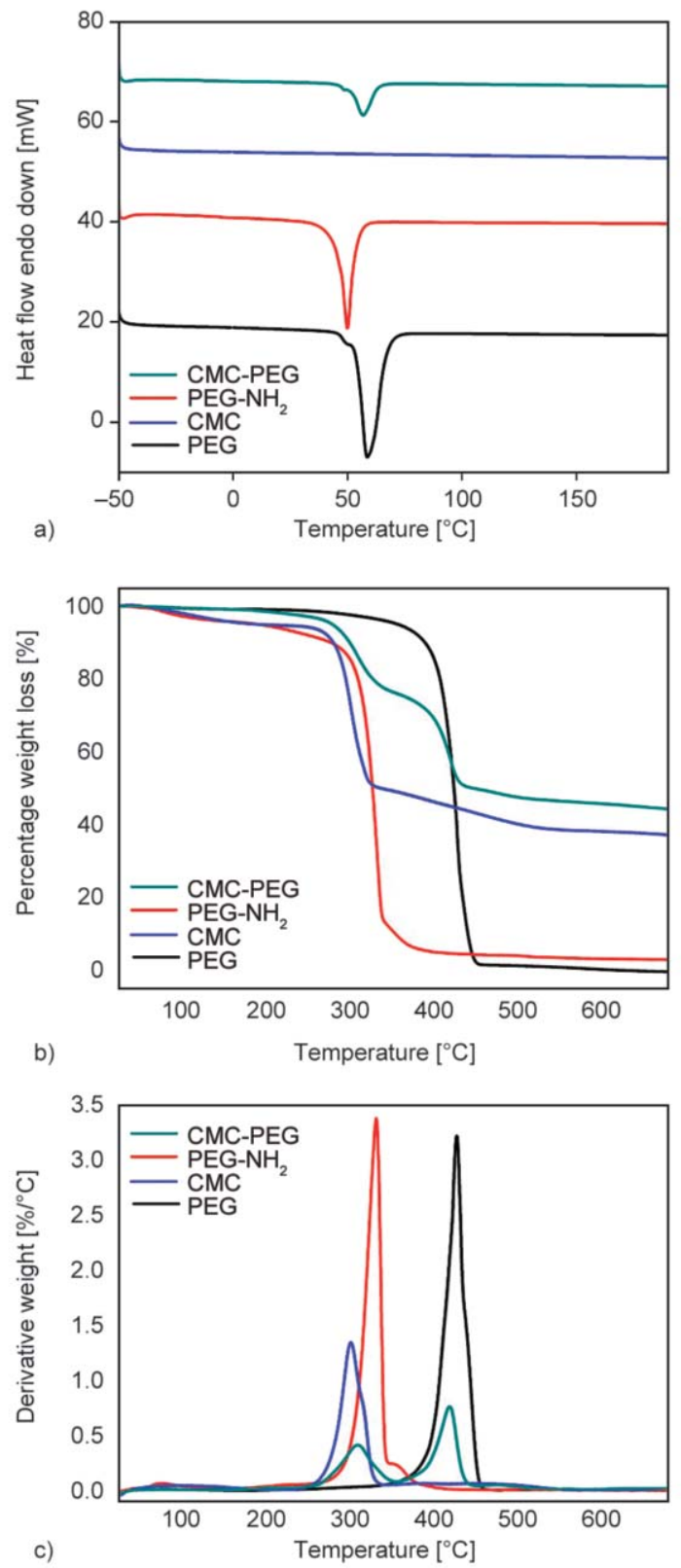

Figure 7. (a) DSC, (b) TGA and (c) derivative TG curves of PEG, PEG-NH,$~ C M C$, and grafted CMC-PEG. melting temperature decreased significantly to $49.91^{\circ} \mathrm{C}$. The thermal property of grafted CMC-PEG (Melting temperature, $T_{\mathrm{m}}=56.80^{\circ} \mathrm{C}$ ) indicates that the product is semi-crystalline. The enthalpy change $\left(\Delta H_{\mathrm{m}}\right)$ of PEG, PEG-NH $\mathrm{N}_{2}$, and grafted CMC-PEG are tabulated in Table 2. This concludes that $\Delta H_{\mathrm{m}}$ decreased due to the $-\mathrm{OH}$ end terminal modification and grafting process, resulting in a reduced crystallinity of grafted CMC-PEG. This result is in line with the findings of XRD in Figure $3 b$.

Thermogravimetric (TGA) and derivative thermogravimetric analyses (DTG) were conducted to investigate the thermal behavior such as decomposition temperature of $\mathrm{CMC}$, $\mathrm{PEG}, \mathrm{PEG}-\mathrm{NH}_{2}$, and grafted CMC-PEG, their percentage of residue, and thermal stability (Figure 7b, 7c and Table 2). The thermal decomposition of PEG started around $355^{\circ} \mathrm{C}$ and decomposed rapidly at $427.97^{\circ} \mathrm{C}$. As PEG has a simple linear chain, the thermal decomposition was assumed to occur at both $-\mathrm{C}-\mathrm{O}$ and $-\mathrm{C}-\mathrm{C}$ bonds of the polymer chain [45]. Interestingly, the amination of PEG to form PEG-NH $\mathrm{N}_{2}$ exhibited a lower decomposition temperature of $331.90^{\circ} \mathrm{C}$. The intermolecular hydrogen bond between - $\mathrm{OH}$ groups is stronger than the one with amine $\left(-\mathrm{NH}_{2}\right)$ groups, which attributes to the lower decomposition temperature [46, 47]. CMC showed a significant weight loss of $5.4 \%$ at low temperature due to the loss of water molecules. The second weight loss was then observed around $301^{\circ} \mathrm{C}$, due to the elimination of $\mathrm{CO}_{2}$ from the decomposition of the hydrocarbon backbone of the polysaccharides. On the other hand, a loss in weight was observed in two stages for grafted CMC-PEG. The first weight loss was recorded at $310^{\circ} \mathrm{C}$, with $17 \%$ caused by the loss of $\mathrm{CO}_{2}$ molecules from the polymeric backbone. A weight loss of $23.7 \%$ was

Table 2. Thermal properties of CMC, PEG, PEG-NH $\mathrm{N}_{2}$ and grafted CMC-PEG.

\begin{tabular}{|l|c|c|c|c|c|}
\hline Polymers & $\begin{array}{c}\boldsymbol{T}_{\mathbf{m}}{ }^{\mathbf{a}} \\
{\left[{ }^{\circ} \mathbf{C}\right]}\end{array}$ & $\begin{array}{c}\Delta \boldsymbol{H}_{\mathbf{m}}{ }^{\mathbf{a}} \\
{[\mathbf{J} / \mathbf{g}]}\end{array}$ & $\begin{array}{c}\boldsymbol{T}_{\mathbf{d}}{ }^{\mathbf{b}} \\
{\left[{ }^{\circ} \mathbf{C}\right)}\end{array}$ & $\begin{array}{c}\boldsymbol{T}_{\max }{ }^{\mathbf{b}} \\
{\left[{ }^{\circ} \mathbf{C}\right]}\end{array}$ & $\begin{array}{c}\mathbf{C h a r ~ y i e l d ~}^{\mathbf{b}} \\
{[\%]}\end{array}$ \\
\hline CMC & - & - & 193.61 & 301.49 & 40.27 \\
\hline PEG & 58.59 & 163.41 & 358.30 & 427.97 & 1.33 \\
\hline $\begin{array}{l}\text { PEG-NH } \\
2\end{array}$ & 49.91 & 95.53 & 191.87 & 331.90 & 4.13 \\
CMC-PEG & 56.80 & 38.15 & 279.32 & 310.00 & 47.67 \\
\hline
\end{tabular}

${ }^{a}$ Melting temperature $\left(T_{\mathrm{m}}\right)$ and enthalpy change $\left(\Delta H_{\mathrm{m}}\right)$ were determined from DSC.

${ }^{b}$ Decomposition temperature $\left(T_{\mathrm{d}}\right)$ at which $5 \%$ mass loss occurs and char yield is defined as the mass percent of residue at $500^{\circ} \mathrm{C}$ were determined from TGA while maximum temperature $\left(T_{\max }\right)$ was determined from DTG curves. 
recorded at $419.07^{\circ} \mathrm{C}$, indicating the thermal decomposition of grafted CMC-PEG. Based on TGA/DTG analysis, the grafting of PEG- $\mathrm{NH}_{2}$ onto the $\mathrm{CMC}$ backbone was shown to improve the thermal stability of grafted CMC-PEG.

\subsection{Cell cytotoxicity}

Cell cytotoxicity of grafted CMC-PEG against NHDFs was quantitatively evaluated using MTS assay. The grafted CMC-PEG was dissolved to concentrations ranging from 0.00001 to $10 \mathrm{mg} / \mathrm{ml}$ followed by culturing with NHDFs for $24 \mathrm{~h}$, as shown in Figure 8. The grafted CMC-PEG exhibited a noncytotoxicity effect towards NHDF cells with percentage cell viability ranging between $100.99 \pm 7.35$ to $98.97 \pm 5.74 \%$ for concentrations below $1 \mathrm{mg} / \mathrm{ml}$. The grafted CMC-PEG with a concentration of $2 \mathrm{mg} / \mathrm{ml}$

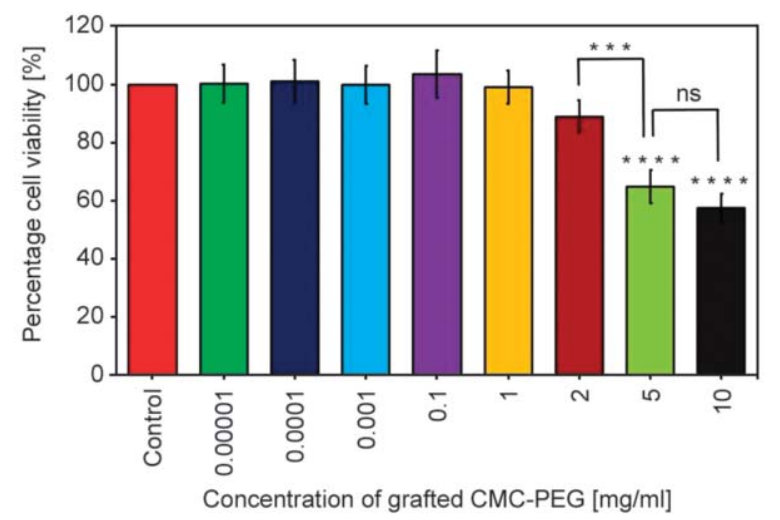

Figure 8. Cell viability of NHDFs after $24 \mathrm{~h}$ incubation (MTS assay) for grafted CMC-PEG with different concentrations ranging from 0.00001 to $10 \mathrm{mg} / \mathrm{ml}$. Data with symbols are significantly different with $p>0.05$ defined as ns, ${ }^{* * *} p \leq 0.001$ and ${ }^{* * *} p \leq 0.0001$.

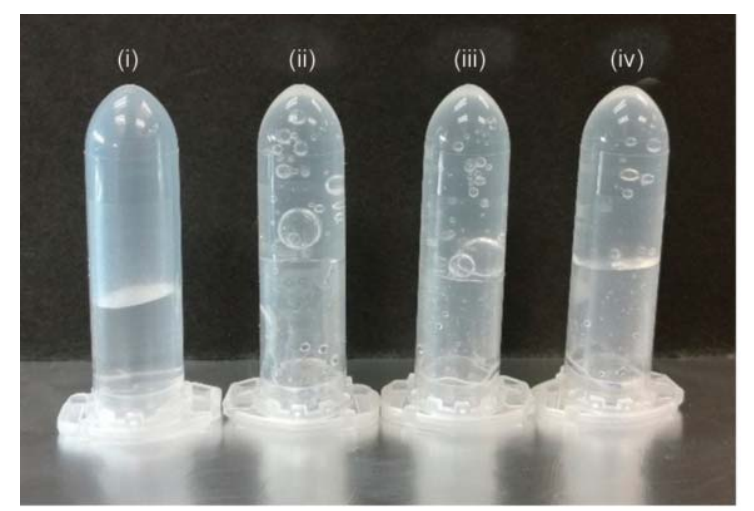

a) showed a slight cytotoxic effect with $88.83 \pm 5.48 \%$ cell viability. Thereafter, the NHDFs viability reduced significantly with increasing concentrations of grafted CMC-PEG to 5 and $10 \mathrm{mg} / \mathrm{ml}$. Based on the findings of the MTS assay, it can be concluded that the grafted CMC-PEG exhibited low cytotoxicity property and excellent biocompatibility for up to $2 \mathrm{mg} / \mathrm{ml}$ of grafted polymer concentration.

\subsection{Rheological analysis}

The citric acid (CA) crosslinked hydrogels formed through the formation of an ester bond between the $-\mathrm{COOH}$ groups of acid and - $\mathrm{OH}$ groups of polysaccharides. This process is known as esterification [48]. Therefore, CA could be used to chemically crosslinked the grafted CMC-PEG to form hydrogels. Then, a rheological analysis was conducted to study the rheological properties of the crosslinked hydrogels as hydrogel inks for 3D-bioprinting or injectable hydrogels. For example, the literature reported that the viscosity of extruding materials for extrusionbased 3D-bioprinting should be between 0.3 to $6000 \mathrm{~Pa} \cdot \mathrm{s}[49,50]$. This information could be useful for the development of hydrogels for specific biomedical applications. In this study, the sol-gel transition and flow behavior of CMC and grafted CMCPEG crosslinked with CA was studied via tube inversion method as shown in Figure 9. An induced flow was observed for uncross-linked $2.5 \%(\mathrm{w} / \mathrm{v}) \mathrm{CMC}$ and $10 \%(\mathrm{w} / \mathrm{v})$ grafted CMC-PEG after tube inversion. This indicates that the samples were not able to maintain the shape, which could limit their potential for advanced biomaterials development [51]. On the other hand, CMC and grafted CMC-PEG formed

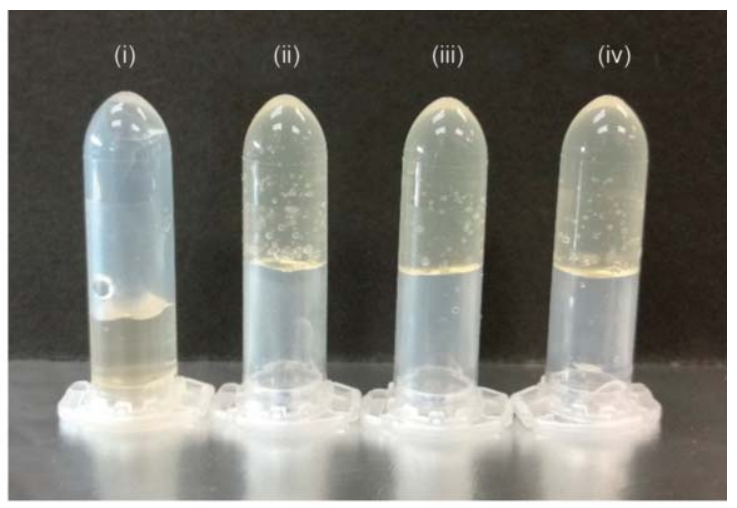

b)

Figure 9. Photographs showing the flow behavior of (a) (i) uncross-linked 2.5\% (w/v) CMC cross-linked, and $2.5 \%$ (w/v) CMC cross-linked with (ii) $5 \%(\mathrm{w} / \mathrm{v})$, (iii) $10 \%$ (w/v) and (iv) $15 \%(\mathrm{w} / \mathrm{v}) \mathrm{CA}$ and (b) (i) uncross-linked 10\% (w/v) grafted CMC-PEG and 10\% (w/v) grafted CMC-PEG crosslinked with (ii) $5 \%(\mathrm{w} / \mathrm{v})$, (iii) $10 \%(\mathrm{w} / \mathrm{v}$ ) and (iv) $15 \%(\mathrm{w} / \mathrm{v}) \mathrm{CA}$ at $37^{\circ} \mathrm{C}$. 
stable hydrogels upon the addition of 5,10 , and $15 \%(\mathrm{w} / \mathrm{v})$ CA crosslinker, respectively. Based on the preliminary studies, $2.5 \%(\mathrm{w} / \mathrm{v}) \mathrm{CMC}$ and $10 \%(\mathrm{w} / \mathrm{v})$ grafted CMC-PEG crosslinked with $5 \%(\mathrm{w} / \mathrm{v})$ CA exhibited shear-thinning behavior and viscosities suitable as injectable hydrogels and hydrogel inks for 3D-bioprinting. These formulations were subjected to further rheological analysis, such as strain-dependent and frequency-dependent studies.

Storage $\left(G^{\prime}\right)$ and loss $\left(G^{\prime \prime}\right)$ moduli measure the extent to which a hydrogel can respond to stress by either absorb energy $\left(G^{\prime}\right)$ or undergo stress relation to dissipate the energy $\left(G^{\prime \prime}\right)$ [52]. For strain-dependent and frequency-dependent studies, the chosen formulations of $2.5 \%(\mathrm{w} / \mathrm{v})$ and $10 \%(\mathrm{w} / \mathrm{v})$ grafted CMCPEG cross-linked with $5 \%(\mathrm{w} / \mathrm{v}) \mathrm{CA}$, represented by $2.5 \% \mathrm{CMC}_{5}$ and $10 \% \mathrm{CMC}^{\mathrm{P}} \mathrm{PG}_{5}$ were studied. The purpose of the strain sweep was to determine the linear viscoelastic region (LVR) and mechanical properties of the crosslinked hydrogels. At low strain $(<20 \%)$, the storage modulus $\left(G^{\prime}\right)$ and loss modulus $\left(G^{\prime \prime}\right)$ of $2.5 \%(\mathrm{w} / \mathrm{v}) \mathrm{CMC}_{5}$ and $10 \%(\mathrm{w} / \mathrm{v}) \mathrm{CMC}-$ $\mathrm{PEG}_{5}$ were constant and parallel with $G^{\prime}>G^{\prime \prime}$ indicating that the materials show a gel-like structure termed as viscoelastic solid material (Figure 10a). At high strain (>40\%), the temporary structure of $10 \%$ CMC-PEG 5 was destroyed, and $G^{\prime}$ started to decrease abruptly, whereas $G^{\prime \prime}$ started to increase, indicating deformation of the gel state [53]. The intersection of $G^{\prime}$ and $G^{\prime \prime}$ of $10 \%(\mathrm{w} / \mathrm{v}) \mathrm{CMC}^{\mathrm{P}}-\mathrm{PEG}_{5}$ at $147 \%$ indicating the collapse of the gel state to a quasi-liquid state [54]. On the other hand, $2.5 \%(\mathrm{w} / \mathrm{v})$ $\mathrm{CMC}_{5}$ hydrogels exhibited viscoelastic fluid characteristics with $G^{\prime}<G^{\prime \prime}$.

Figure $10 \mathrm{~b}$ presents $G^{\prime}$ and $G^{\prime \prime}$ of $2.5 \%(\mathrm{w} / \mathrm{v}) \mathrm{CMC}_{5}$ and $10 \%(\mathrm{w} / \mathrm{v}) \mathrm{CMC}^{-} \mathrm{PEG}_{5}$ hydrogels as a function of angular frequency ranging from 0.1 to $100 \mathrm{rad} / \mathrm{s}$ at $0.5 \%$ strain. The frequency-dependent test measures the time-dependent viscoelastic properties of the crosslinked hydrogel network within the non-destructive LVR region [55]. The high frequency represents short-term behavior such as mixing and extruding; meanwhile, the low frequency indicates longterm behavior such as settling [56]. The $10 \%(\mathrm{w} / \mathrm{v})$ CMC-PEG5 hydrogel exhibit a sharp increase of $G^{\prime}$ at higher frequencies, indicating a 'solid-like' behavior predominates and gel stability due to the $3 \mathrm{D}$ structure of the crosslinked hydrogels. However, the G' of $2.5 \%$ (w/v) CMC5 hydrogel decreased abruptly at higher frequencies $\left(G^{\prime}<G^{\prime}\right)$ with cross-over between $G^{\prime}$ and $G^{\prime \prime}$ which indicates the viscoelastic liquid properties with undefined network structure. Based on the rheological studies, $10 \%$ (w/v) CMC$\mathrm{PEG}_{5}$ hydrogel showed enhanced mechanical properties and promising rheological properties compared to $2.5 \%(\mathrm{w} / \mathrm{v}) \mathrm{CMC} 5$ hydrogel.

\section{Conclusions}

In the present work, grafted CMC-PEG was successfully synthesized in the presence of EDC and NHS as the activators. FT-IR confirmed the amination of PEG and grafting of PEG-NH$H_{2}$ to the CMC backbone through the formation of an amide bond. The successful grafting was also confirmed by ${ }^{1} \mathrm{H}$ NMR and solid-state ${ }^{13} \mathrm{C}$ CPMAS NMR due to the appearance of characteristic peaks around 7 and 174 ppm corresponded to the proton and carbon of the amide group. XRD findings of grafted CMC-PEG showed a semi-crystalline nature. Thermal studies by DSC further confirmed the semi-crystalline nature of grafted CMC-PEG, while TGA showed enhanced thermal stability compared to the polymer substrates. In vitro cytotoxicity assay confirmed the non-cytotoxic property of grafted CMC-PEG and excellent
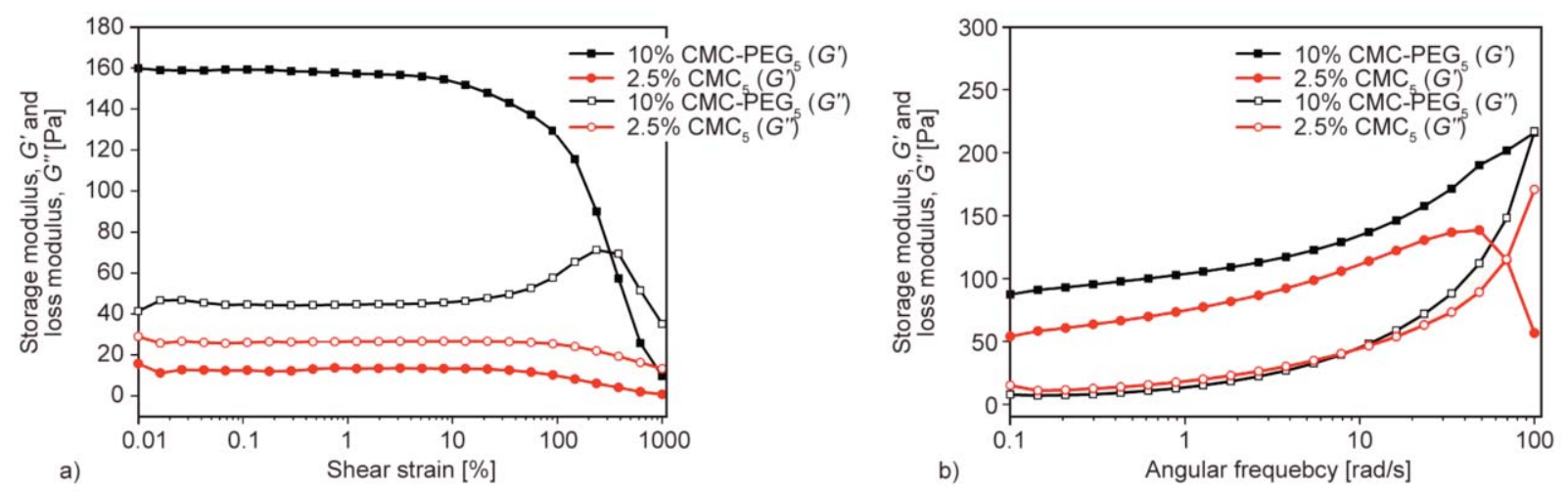

Figure 10. (a) Strain-dependent and (b) frequency-dependent oscillatory shear rheology of the hydrogels. *Hydrogels with subscript 5 indicate the $5 \%(\mathrm{w} / \mathrm{v})$ percentage composition of CA in the crosslinked hydrogel samples. 
biocompatibility with NHDFs. The rheological analysis reported that grafted CMC-PEG crosslinked with CA improved the hydrogel's viscosity. The further rheological analysis found $10 \%(\mathrm{w} / \mathrm{v})$ grafted CMCPEG crosslinked with 5\% (w/v) CA to be the best hydrogel formulation with improved mechanical property compared to the CMC crosslinked with $5 \%(\mathrm{w} / \mathrm{v}) \mathrm{CA}$. The hydrogel of grafted CMC-PEG demonstrated potential use as hydrogel inks for 3Dbioprinting and injectable hydrogels for various biomedical applications such as tissue engineering, drug delivery system, and wound dressing materials.

\section{Acknowledgements}

The authors acknowledge the financial support from Monash University Malaysia through the Higher Degree Research (HDR) student fund. The authors are thankful to Associate Professor Kei Saito for supporting the usage of instruments at the School of Chemistry, Monash University Australia.

\section{References}

[1] Hai T. A. P., Matsukuma H., Sugimoto R.: Grafting poly (3-hexylthiophene) to the surface of polypropylene using oxidative polymerization. Polymer, 121, 247-255 (2017). https://doi.org/10.1016/j.polymer.2017.06.027

[2] Wu C-S.: A comparison of the structure, thermal properties, and biodegradability of polycaprolactone/chitosan and acrylic acid grafted polycaprolactone/chitosan. Polymer, 46, 147-155 (2005).

https://doi.org/10.1016/j.polymer.2004.11.013

[3] Vaidya A. A., Hussain I., Gaugler M., Smith D. A.: Synthesis of graft copolymers of chitosan-poly(caprolactone) by lipase catalysed reactive extrusion. Carbohydrate Polymers, 217, 98-109 (2019).

https://doi.org/10.1016/j.carbpol.2019.03.081

[4] Kato K., Uchida E., Kang E-T., Uyama Y., Ikada Y.: Polymer surface with graft chains. Progress in Polymer Science, 28, 209-259 (2003). https://doi.org/10.1016/S0079-6700(02)00032-1

[5] Liu Y., Zhao K.: Rheological and dielectric behavior of milk/sodium carboxymethylcellulose mixtures at various temperatures. Journal of Molecular Liquids, 290, 111175/1-111175/7 (2019). https://doi.org/10.1016/j.molliq.2019.111175

[6] Fekete T., Borsa J., Takács E., Wojnárovits L.: Synthesis of carboxymethylcellulose/acrylic acid hydrogels with superabsorbent properties by radiation-initiated crosslinking. Radiation Physics and Chemistry, 124, 135139 (2016).

https://doi.org/10.1016/j.radphyschem.2015.09.018

[7] Candido R. G., Gonçalves A. R.: Synthesis of cellulose acetate and carboxymethylcellulose from sugarcane straw. Carbohydrate Polymers, 152, 679-686 (2016). https://doi.org/10.1016/j.carbpol.2016.07.071
[8] Kono H.: Characterization and properties of carboxymethyl cellulose hydrogels crosslinked by polyethylene glycol. Carbohydrate Polymers, 106, 84-93 (2014). https://doi.org/10.1016/j.carbpol.2014.02.020

[9] Ghorpade V. S., Yadav A. V., Dias R. J., Mali K. K., Pargaonkar S. S., Shinde P. V., Dhane N. S.: Citric acid crosslinked carboxymethylcellulose-poly (ethylene glycol) hydrogel films for delivery of poorly soluble drugs. International Journal of Biological Macromolecules, 118, 783-791 (2018). https://doi.org/10.1016/j.ijbiomac.2018.06.142

[10] Kumar B., Negi Y. S.: Water absorption and viscosity behaviour of thermally stable novel graft copolymer of carboxymethyl cellulose and poly(sodium 1-hydroxy acrylate). Carbohydrate Polymers, 181, 862-870 (2018).

https://doi.org/10.1016/j.carbpol.2017.11.066

[11] Alange V. V., Birajdar R. P., Kulkarni R. V.: Novel spray dried $\mathrm{pH}$-sensitive polyacrylamide-grafted-carboxymethylcellulose sodium copolymer microspheres for colon targeted delivery of an anti-cancer drug. Journal of Biomaterials Science, Polymer Edition, 28, 139-161 (2017).

https://doi.org/10.1080/09205063.2016.1257083

[12] Dahlan N. A., Pushpamalar J., Veeramachineni A. K., Muniyandy S.: Smart hydrogel of carboxymethyl cellulose grafted carboxymethyl polyvinyl alcohol and properties studied for future material applications. Journal of Polymers and the Environment, 26, 2061-2071 (2018).

https://doi.org/10.1007/s10924-017-1105-3

[13] Li H., Liu S., Lin L.: Rheological study on 3D printability of alginate hydrogel and effect of graphene oxide. International Journal of Bioprinting, 2, 54-66 (2016). https://doi.org/10.18063/IJB.2016.02.007

[14] Drury J. L., Mooney D. J.: Hydrogels for tissue engineering: Scaffold design variables and applications. Biomaterials, 24, 4337-4351 (2003). https://doi.org/10.1016/S0142-9612(03)00340-5

[15] Namazi H., Rakhshaei R., Hamishehkar H., Kafil H. S.: Antibiotic loaded carboxymethylcellulose/MCM-41 nanocomposite hydrogel films as potential wound dressing. International Journal of Biological Macromolecules, 85, 327-334 (2016).

https://doi.org/10.1016/j.ijbiomac.2015.12.076

[16] Ghorpade V. S., Yadav A. V., Dias R. J.: Citric acid crosslinked $\beta$-cyclodextrin/carboxymethylcellulose hydrogel films for controlled delivery of poorly soluble drugs. Carbohydrate Polymers, 164, 339-348 (2017). https://doi.org/10.1016/j.carbpol.2017.02.005

[17] Lee S., Park Y. H., Ki C. S.: Fabrication of PEG-carboxymethylcellulose hydrogel by thiol-norbornene photo-click chemistry. International Journal of Biological Macromolecules, 83, 1-8 (2016). https://doi.org/10.1016/j.ijbiomac.2015.11.050 
[18] Bang S., Ko Y-G., Kim W. I., Cho D., Park W. H., Kwon O. H.: Preventing postoperative tissue adhesion using injectable carboxymethyl cellulose-pullulan hydrogels. International Journal of Biological Macromolecules, 105, 886-893 (2017).

https://doi.org/10.1016/j.ijbiomac.2017.07.103

[19] Gaihre B., Jayasuriya A. C.: Fabrication and characterization of carboxymethyl cellulose novel microparticles for bone tissue engineering. Materials Science and Engineering: C, 69, 733-743 (2016). https://doi.org/10.1016/j.msec.2016.07.060

[20] Cameron D. J. A., Bissessur R., Dahn D. C.: Synthesis and characterization of poly(ethylene glycol amine) electrolytes and nanocomposites based on graphite. European Polymer Journal, 48, 1525-1537 (2012). https://doi.org/10.1016/j.eurpolymj.2012.05.018

[21] Guler Z., Sarac A.: Electrochemical impedance and spectroscopy study of the EDC/NHS activation of the carboxyl groups on poly(e-caprolactone)/poly(m-anthranilic acid) nanofibers. Express Polymer Letters, 10, 96-110 (2016).

https://doi.org/10.3144/expresspolymlett.2016.11

[22] Kumar A., Sharma S., Kumar R.: The graft copolymerization of $N$-vinyl-2-pyrrolidone onto carboxymethyl cellulose and its application for controlled release of water-soluble levofloxacin. Journal of Polymer Research, 27, 46/1-46/9 (2020).

https://doi.org/10.1007/s10965-020-2023-y

[23] Pettignano A., Charlot A., Fleury E.: Carboxyl-functionalized derivatives of carboxymethyl cellulose: Towards advanced biomedical applications. Polymer Reviews, 59, 510-560 (2019).

https://doi.org/10.1080/15583724.2019.1579226

[24] Kumar D., Pandey J., Raj V., Kumar P.: A review on the modification of polysaccharide through graft copolymerization for various potential applications. The Open Medicinal Chemistry Journal, 11, 109-126 (2017). https://doi.org/10.2174/1874104501711010109

[25] Mahou R., Wandrey C.: Versatile route to synthesize heterobifunctional poly(ethylene glycol) of variable functionality for subsequent pegylation. Polymers, 4, 561-589 (2012).

https://doi.org/10.3390/polym4010561

[26] Piegat A., Goszczyńska A., Idzik T., Niemczyk A.: The importance of reaction conditions on the chemical structure of N,O-acylated chitosan derivatives. Molecules, 24, 3047/1-3047/16 (2019).

https://doi.org/10.3390/molecules24173047

[27] Kumar D., Rub M. A., Asiri A. M.: Synthesis and characterization of geminis and implications of their micellar solution on ninhydrin and metal amino acid complex. Royal Society Open Science, 7, 200775/1200775/13 (2020).

https://doi.org/10.1098/rsos.200775
[28] Baharifar H., Khoobi M., Bidgoli S. A., Amani A.: Preparation of PEG-grafted chitosan/streptokinase nanoparticles to improve biological half-life and reduce immunogenicity of the enzyme. International Journal of Biological Macromolecules, 143, 181-189 (2020). https://doi.org/10.1016/j.ijbiomac.2019.11.157

[29] Tan B., Huang Z., Yin Z., Min X., Liu Y., Wu X., Fang M.: Preparation and thermal properties of shape-stabilized composite phase change materials based on polyethylene glycol and porous carbon prepared from potato. RSC Advances, 6, 15821-15830 (2016). https://doi.org/10.1039/C5RA25685B

[30] Zhang X., Yao J., Zhang L., Fang J., Bian F.: Synthesis and characterization of PEG-conjugated quaternized chitosan and its application as a gene vector. Carbohydrate Polymers, 103, 566-572 (2014).

https://doi.org/10.1016/j.carbpol.2013.12.072

[31] Badwaik H. R., Sakure K., Alexander A., Ajazuddin, Dhongade H., Tripathi D. K.: Synthesis and characterisation of poly(acryalamide) grafted carboxymethyl xanthan gum copolymer. International Journal of Biological Macromolecules, 85, 361-369 (2016). https://doi.org/10.1016/j.ijbiomac.2016.01.014

[32] Yang Y., Liu Y., Chen S., Cheong K-L., Teng B.: Carboxymethyl $\beta$-cyclodextrin grafted carboxymethyl chitosan hydrogel-based microparticles for oral insulin delivery. Carbohydrate Polymers, 246, 116617/1-116617/9 (2020).

https://doi.org/10.1016/j.carbpol.2020.116617

[33] Takeshita H., Sasagawa G., Takenaka K., Miya M., Shiomi T.: Crystallization of graft copolymers 1. Graft chains miscible with main chains. Polymer Journal, 42, 482-488 (2010).

https://doi.org/10.1038/pj.2010.24

[34] Sugiyama F., Kleinschmidt A. T., Kayser L. V., Rodriquez D., Finn M., Alkhadra M. A., Wan J. M-H., Ramírez J., Chiang A. S-C., Root S. E., Savagatrup S., Lipomi D. J.: Effects of flexibility and branching of side chains on the mechanical properties of low-bandgap conjugated polymers. Polymer Chemistry, 9, 4354-4363 (2018). https://doi.org/10.1039/C8PY00820E

[35] Ciftci M.: Synthesis of graft copolymers by combination of radical photopolymerization and iniferter process. Journal of Polymer Science Part A: Polymer Chemistry, 57, 1344-1348 (2019). https://doi.org/10.1002/pola.29395

[36] Dao T. P. T., Nguyen T. H., To V. V., Ho T. H., Nguyen T. A., Dang M. C.: A new formulation of curcumin using poly(lactic-co-glycolic acid)-polyethylene glycol diblock copolymer as carrier material. Advances in Natural Sciences: Nanoscience and Nanotechnology, 5, 035013/1-035013/7 (2014).

https://doi.org/10.1088/2043-6262/5/3/035013 
[37] Veeramachineni A. K., Sathasivam T., Muniyandy S., Janarthanan P., Langford S. J., Yan L. Y.: Optimizing extraction of cellulose and synthesizing pharmaceutical grade carboxymethyl sago cellulose from Malaysian sago pulp. Applied Sciences, 6, 170/1-170/18 (2016). https://doi.org/10.3390/app6060170

[38] Jiang W., Yang L., Qiu L., Xu J., Yang X., Wang J., Zhou H., Wang D.: Multifunctional hybrid nanoparticles based on sodium carboxymethylcellulose-graft-histidine and TPGS for enhanced effect of docetaxel. RSC Advances, 5, 53835-53845 (2015). https://doi.org/10.1039/C5RA05586E

[39] Capanema N. S., Mansur A. A., Mansur H. S., de Jesus A. C., Carvalho S. M., Chagas P., de Oliveira L. C.: Ecofriendly and biocompatible cross-linked carboxymethylcellulose hydrogels as adsorbents for the removal of organic dye pollutants for environmental applications. Environmental Technology, 39, 2856-2872 (2018). https://doi.org/10.1080/09593330.2017.1367845

[40] Li H-L., He Y-X., Gao Q-H., Wu G-Z.: Folate-polyethylene glycol conjugated carboxymethyl chitosan for tumor-targeted delivery of 5-fluorouracil. Molecular Medicine Reports, 9, 786-792 (2014).

https://doi.org/10.3892/mmr.2014.1917

[41] Kono H.: $1 \mathrm{H}$ and $13 \mathrm{C}$ chemical shift assignment of the monomers that comprise carboxymethyl cellulose. Carbohydrate Polymers, 97, 384-390 (2013).

https://doi.org/10.1016/j.carbpol.2013.05.031

[42] Dai H., Zhang Y., Ma L., Zhang H., Huang H.: Synthesis and response of pineapple peel carboxymethyl cellulose-g-poly (acrylic acid-co-acrylamide)/graphene oxide hydrogels. Carbohydrate Polymers, 215, 366-376 (2019).

https://doi.org/10.1016/j.carbpol.2019.03.090

[43] Li J., Fang L., Tait W. R., Sun L., Zhao L., Qian L.: Preparation of conductive composite hydrogels from carboxymethyl cellulose and polyaniline with a nontoxic crosslinking agent. RSC Advances, 7, 54823-54828 (2017).

https://doi.org/10.1039/C7RA10788A

[44] Goswami A., Bajpai A. K., Bajpai J., Sinha B. K.: Designing vanadium pentoxide-carboxymethyl cellulose/ polyvinyl alcohol-based bionanocomposite films and study of their structure, topography, mechanical, electrical and optical behavior. Polymer Bulletin, 75, $781-$ 807 (2018).

https://doi.org/10.1007/s00289-017-2067-2

[45] Kwon S. K., Kim D. H.: Effect of process parameters of UV-assisted gas-phase cleaning on the removal of PEG (polyethyleneglycol) from a Si substrate. Journal Korean Physical Society, 49, 1421-1427 (2006).

[46] Awada H., Daneault C.: Chemical modification of poly (vinyl alcohol) in water. Applied Sciences, 5, 840-850 (2015).

https://doi.org/10.3390/app5040840
[47] Neto C. G. T., Giacometti J. A., Job A. E., Ferreira F. C., Fonseca J. L. C., Pereira M. R.: Thermal analysis of chitosan based networks. Carbohydrate Polymers, 62, 97-103 (2005).

https://doi.org/10.1016/j.carbpol.2005.02.022

[48] Uranga J., Nguyen B. T., Si T. T., Guerrero P., de la Caba K.: The effect of cross-linking with citric acid on the properties of agar/fish gelatin films. Polymers, 12, 291/1-291/12 (2020).

https://doi.org/10.3390/polym12020291

[49] Derakhshanfar S., Mbeleck R., Xu K., Zhang X., Zhong W., Xing M.: 3D bioprinting for biomedical devices and tissue engineering: A review of recent trends and advances. Bioactive Materials, 3, 144-156 (2018).

https://doi.org/10.1016/j.bioactmat.2017.11.008

[50] He Y., Yang F., Zhao H., Gao Q., Xia B., Fu J.: Research on the printability of hydrogels in 3D bioprinting. Scientific Reports, 6, 29977/1-29977/13 (2016). https://doi.org/10.1038/srep29977

[51] Li H., Tan Y. J., Leong K. F., Li L.: 3D bioprinting of highly thixotropic alginate/methylcellulose hydrogel with strong interface bonding. ACS Applied Materials and Interfaces, 9, 20086-20097 (2017).

https://doi.org/10.1021/acsami.7b04216

[52] Chen M. H., Wang L. L., Chung J. J., Kim Y-H., Atluri P., Burdick J. A.: Methods to assess shear-thinning hydrogels for application as injectable biomaterials. ACS Biomaterials Science and Engineering, 3, 3146-3160 (2017). https://doi.org/10.1021/acsbiomaterials.7b00734

[53] Ou K., Dong X., Qin C., Ji X., He J.: Properties and toughening mechanisms of PVA/PAM double-network hydrogels prepared by freeze-thawing and annealswelling. Materials Science and Engineering: C, 77, 1017-1026 (2017).

https://doi.org/10.1016/j.msec.2017.03.287

[54] Gačanin J., Kovtun A., Fischer S., Schwager V., Quambusch J., Kuan S. L., Liu W., Boldt F., Li C., Yang Z., Liu D., Wu Y., Weil T., Barth H., Ignatius A.: Spatiotemporally controlled release of rho inhibiting C3 toxin from a protein-DNA hybrid hydrogel for targeted inhibition of osteoclast formation and activity. Advanced Healthcare Materials, 6, 1700392/1-1700392/12 (2017). https://doi.org/10.1002/adhm.201700392

[55] Zuidema J. M., Rivet C. J., Gilbert R. J., Morrison F. A.: A protocol for rheological characterization of hydrogels for tissue engineering strategies. Journal of Biomedical Materials Research Part B: Applied Biomaterials, 102, 1063-1073 (2014).

https://doi.org/10.1002/jbm.b.33088

[56] Paxton N., Smolan W., Böck T., Melchels F., Groll J., Jungst T.: Proposal to assess printability of bioinks for extrusion-based bioprinting and evaluation of rheological properties governing bioprintability. Biofabrication, 9, 044107/1-044107/18 (2017). https://doi.org/10.1088/1758-5090/aa8dd8 